2022-02

\title{
APPROACHES TOWARDS \\ ELUCIDATING EMOTIONAL \\ RESPONSES TO MUSIC THEATRE
}

\section{Green, Ryan}

http://hdl.handle.net/10026.1/18757

\subsection{7/TOR2022TRANS.VOL7.12}

TRANSFORMATION

South West Doctoral Training Partnership

All content in PEARL is protected by copyright law. Author manuscripts are made available in accordance with publisher policies. Please cite only the published version using the details provided on the item record or document. In the absence of an open licence (e.g. Creative Commons), permissions for further reuse of content should be sought from the publisher or author. 


\section{APPROACHES TOWARDS ELUCIDATING EMOTIONAL RESPONSES TO MUSIC THEATRE}

\section{RYAN THOMAS GREEN}

As a result of recent publications in the field of music theatre there has been a resurgence of interest in this highly misunderstood art form. This paper discusses the methodology and results from an online survey which investigated emotional responses to orchestration ${ }^{1}$ and instrumental aesthetics in contemporary music theatre. This report summarises the current literature, demonstrates gaps in the field, and suggests how further research may benefit the development of new music theatre. The research tests the hypothesis that music theatre is accidentally alienating to non-familiar audiences because of its complex musical language and perceived associations with opera and the ever-popular Broadway/West End musical. Since the 1960s, music theatre has been used to express artistic experimentalism in music performance. This paper aims to elucidate the connections between the instrumental and orchestration choices made by music theatre composers and the effects they have on a modern audience to identify key indexes which may indicate the art form's failure to capture audience imaginations or to engage audiences emotionally. This research indicates that audiences generally have a good perception of instrumentation in music theatre. There is also evidence to support the hypothesis that there is a connection between lack of aesthetic appreciation (the admiration of beaty in art) and negative emotional response. However there remains a gap in our understanding of the abstract nature of music theatre, which some audience members struggle to comprehend or engage with emotionally. 


\section{INTRODUCTION}

The emergence of music theatre in the 1960s and 1970s was followed by academic interest in the art form. The art form was seen to have emerged as a response to dissatisfaction with operatic practice (Verstraete, 2009: 2), and it challenged conventional methods of presenting music performance. The British Theatres Act (1968), which allowed authorities to censor performances, was repealed, allowing practitioners and composers to advance new forms of expression. In more recent years, music theatre has been the subject of discourse by academics attempting to either circumscribe the boundaries of the art form or group it with opera. Anthony Gilbert, Harrison Birtwistle, Peter Maxwell Davies and Alexander Goehr (or to use Robert Adlington's phrase, the 'Manchester generation' (2018: 435)) sought to create a form disassociated from opera which occupied the space between the music performance and theatrical performance. Hall writes that Gilbert 'took the bull by the horns by attacking the whole concept of traditional opera [...]. He felt that composers should develop a much more concentrated form of opera, which would be relevant in 'contemporary situations" (2015: 16)

Psychology has already been explored as a phenomenon in the realm of music theatre. Peter Maxwell Davies explored the humanisation of madness and poor mental states within his music theatre works Eight Songs for a Mad King (1969) and Miss Donnithorn's Maggot (1974). However, while psychological states have been explored artistically, there has been little to capture the emotional responses of the audience member who endures such depictions of trauma from a bystander's perspective.

The rationale for this study comes from a desire to understand how to engage new audiences with this highly versatile art form in a way which is relatable and relevant for modern audiences. Coker (2006) implies that while opera fails to capture the imagination of young people, by contrast musical theatre has become an extremely popular art form with increasing number of shows transferring to big screen cinema and becoming post-theatrical events. This study aims to increase awareness of the versatility and potential of the music theatre art form.

\section{A. Literature}

Music Theatre has been discussed widely in current literature as a result of a recent uplift of academic interest in the art form (ITI Germany \& Rebstock, 2020; Aldington, 2020). Literature indicates dissatisfaction with the traditions of opera and theatre (Verstraete, 2009; Devlin, 1992). Rebstock calls for further research, commenting that 'our understanding of independent music theatre would [...] benefit from a detailed inquiry into domains from which individual composers have emerged' (2020: 281).

Researchers have previously identified the widespread lack of understanding of the music theatre art form. Graham Devlin writes in his 1992 report that 'it may be useful to mount a generic marketing campaign explaining what "music-theatre" is. Other approaches might also have the aim of making the work more comprehensible to the general public' (1992: 78).

Several studies have sought to examine audience responses to music theatre. Boerner and Jobst (2008; 2011; 2013) carried out research at the Dessau Opera House in Germany, surveying the 2007 performance of Mozart's The Magic Flute. However, their survey design was flawed because it only collected quantitative data from which they were unable to draw concrete conclusions, and in several of their papers they did not offer a conclusion at all. A similar survey was carried out by Chan et al. (2019) which collected audience evaluations of emotion, sensation and authenticity of opera and music theatre in Hong Kong. The paper concluded that there was a 'lack of concern for connectedness' which could point towards the 'distinct cultural or geographical nature of the theatrescape in Hong Kong' (Chan et al., 2019: 18). Furthermore, the paper's main aim was to collect information from 'experts', rather than the average theatre-goer, rendering the data biased. Collecting data from 'experts' invites the assumption that only those with a certain level of education are able to appreciate the aesthetics and nuances of the theatre and thus ignores a valuable potential data set of responses of non-'experts'.

A study which aimed to capture young people's attitudes towards music theatre was carried out by Tim Coker in 2006. A group of sixth form students from Essex were asked to watch a 2004 production of The Tempest. Coker observed that the students remarked on the staging and were impressed by the set's design and lighting (Coker, 2006: 40). He noted that while the opening music captured their imagination, they quickly lost interest as the production went on, with discussions referring to a 'lack of contrast' in the character's voices (2006: 41). The students also tended to disengage rather than concentrate when the music became 'difficult'. Coker did not elaborate on the term 'difficult' however, one interpretation may be that the musical language became overwhelming. Coker concluded that because 'MTV' culture has become an intrinsic part of our everyday lives, in order for opera to engage younger generations, it also needs to supply 'the sound bites we crave' (ibid.). Coker noted that the opera 'remained too intense and too dense for too long', and called for a more dramatic and immediate score (ibid.). 
The current literature demonstrates a gap in research on psychological responses to experimental music theatre work. More specifically, there is little research investigating audiences' emotional responses to instrumental and orchestration aesthetics within this art form. There is also a lack of research which bridges music psychology and music theatre. Further investigation will allow for the formation of new research hypotheses and may broaden how music theatre is created, making it relevant for modern audiences and potentially breaking away from opera. As Eric Salzman observes, music theatre is to opera as modern dance is to ballet (2002: 63), implying that a separation of opera from music theatre might be necessary. Although there is sufficient theory in the field of musical aesthetics, further theory will need to be developed which will be appropriate for the discussion of aesthetics in music theatre

\section{METHODOLOGY}

This section will describe the methodology used for this study. Participants were asked to watch and listen to a set of music theatre video clips ${ }^{2}$ and were then asked questions based on what they had seen and heard. The clips chosen were those which best captured my own imagination as the most emotionally evocative.

An online survey was used to collect data from a wide range of demographics. In total there were responses from forty-eight participants, who were recruited through email and social media sites. The methodology for this survey was primarily concerned with collecting qualitative data, such as emotional responses and aesthetic responses, however quantitative data such as age range were also collected. Volunteers were asked to give informed consent to participate and were advised that only the research team could see their initials. Some of the material presented in some excerpts contained potential emotional triggers such as references to slavery, racism, violence, and abuse - these were clearly marked in red above the relevant videos ${ }^{3}$. Ethical approval was granted by the University Ethics and Integrity committee in April 2021.

Questions varied in openness and consisted of three sections, each divided into four sub-sections, totalling 25 questions in total. The survey was designed to take no longer than half an hour, was open to anyone, and had no pre-requisites or screening process prior to answering the questions. The type of answers varied from single and multiple-choice options to unlimited answer boxes. Although this method of collection has many caveats, it was found to be the best option to reach a large sample size. Data was collected through the 'Jisc' online survey platform, which is General Data Protection Regulation (GDPR) compliant.

There are potential disadvantages in using this research method. Participants were not present in the room with the researcher, which may prevent rapport-building and preclude the opportunity to tease out further answers. As participants' replies are not regulated by the researcher this can result in careless or unfounded comments, or provide irrelevant information or incomplete ideas. This method of research creates distance between the researcher and participant; therefore their reactions and interest cannot be observed, potentially eradicating an interesting data set. However, a crucial advantage is that by conducting a survey in this way, there is no risk of influential bias from the researcher.

Another potential barrier may occur if the participant lacks the appropriate lexical language to clearly articulate the musical information that we are trying to procure. It should be noted that all but three participants answered that they could play a musical instrument. It would be unfair, and potentially off-putting, to expect the average theatregoer to employ technical terminology such as 'legato', 'crescendo', 'piano' or 'forte', analytical syntax which some may see as overwhelming technical 'jargon'. Therefore, a mix of lexical language was chosen to help participants from a non-musical background to articulate their feelings using language they felt comfortable with, without making them feel ignorant or un-educated. Several questions asked participants to justify their answers, thus increasing validity (when completed) and allowing the provision of additional comments which may be of interest to the researcher.

\section{RESULTS AND DISCUSSION}

This section will present the data collected from the online questionnaire surveys. This section is split into two case studies with a total of three sections. The first section demonstrates sample background information such as age, qualification level, ability to perform musical instruments and general understanding of the term 'orchestration'. The second section contains questions relating to Case Study $A$; the final section contains questions relating to Cast Study B. 


\section{A. Section 1: Sample Background Information}

The age range of the sample was 25-54 years, with all participants holding some form of academic qualification at GCSE level or above. Of the 48 participants, 39 played a musical instrument. To form an overview of the types of performance participants had already seen, they were asked to choose all that applied (Figure 1). This question established that all but one person had some awareness of what it is to experience live performance art in one way or another.

To your knowledge, have you ever attended any of the following performance genres?

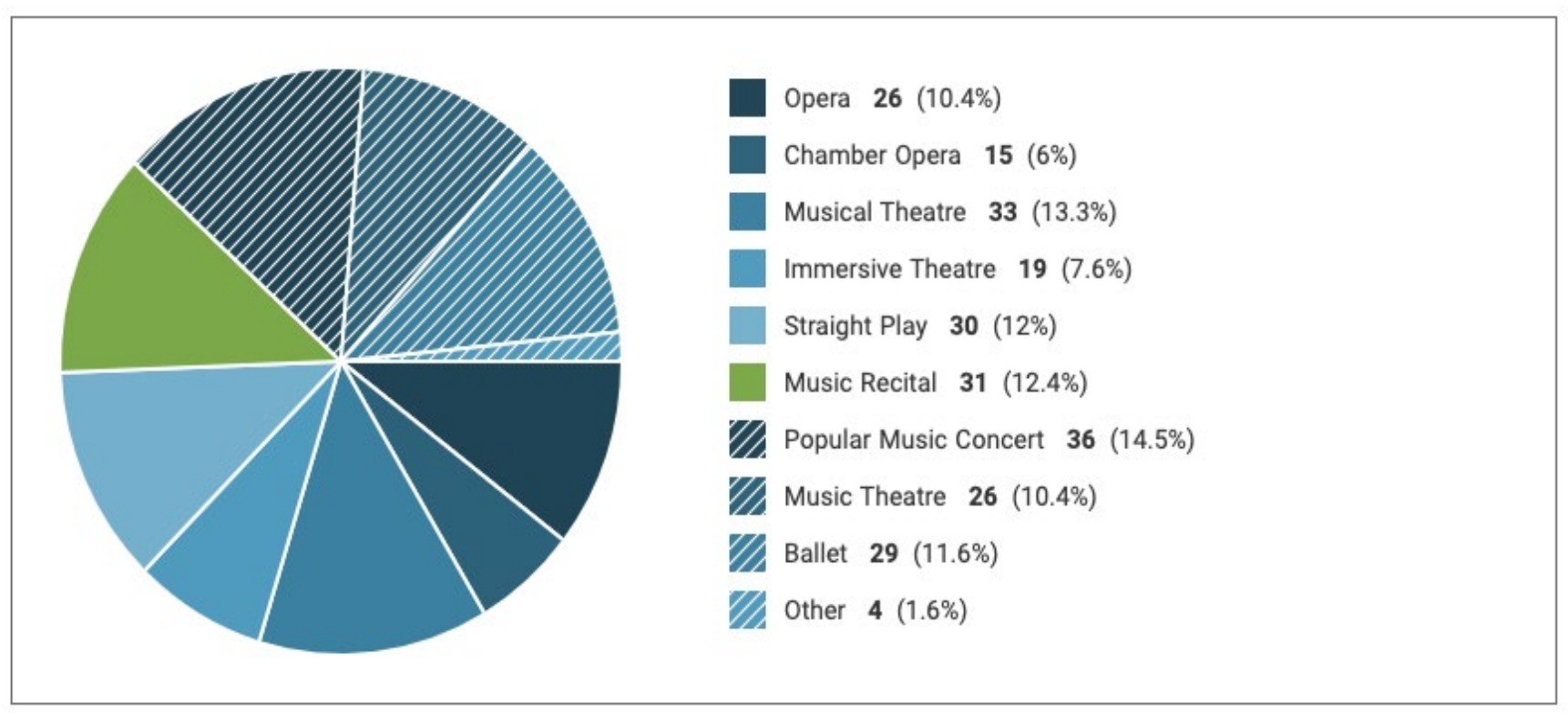

Figure 1: Previous Attendance of Performance Genres

None of the genre options were pre-defined, inviting interpretation from the participants themselves. The most commonly attended performance art was 'popular music concert' (14.5\%). Four participants answered 'other' with some interesting remarks, for example, one participant observed online performances during the 'COVID year', which they considered a new type of performance genre. Other answers included 'folk/ ethnic performance' and 'free form/experimental/poetry performance'. A surprisingly high number had seen a work of music theatre. It may be prudent in future to ask whether participants already have an understanding of the art form or provide them with a clearer definition.

Participants were then asked to 'select below your understanding of the term "orchestration"'4. The highest number of participants (28.5\%) chose 'the way the instruments are employed in order to perform a piece of music' and 'the combination of instruments used in a piece of music'. One participant was unsure, however it is interesting that they did not make a contextual guess but instead answered honestly. Directly following this question participants were asked if they had 'any other thoughts?'. No further comments were made.

\section{B. Case Study One: SWEET TOOTH (2018)}

Participants were invited to watch a minute-long video of the live performance of SWEET TOOTH (2018) by Elaine Mitchener. SWEET TOOTH is a raw and intimate portrayal of the history of the sugar trade. This particular clip showed the saxophonist and Mitchener who will be referred to as the performer. Participants were first asked to use their own words to describe what they felt the composer was attempting to portray through their music in the excerpt. Most participants described pain and suffering, with some citing the feeling of being overwhelmed by the musical's depiction of the treatment of slaves. A word cloud was created (Figure 2) to highlight the words used by participants, with the most commonly mentioned words in larger type. 


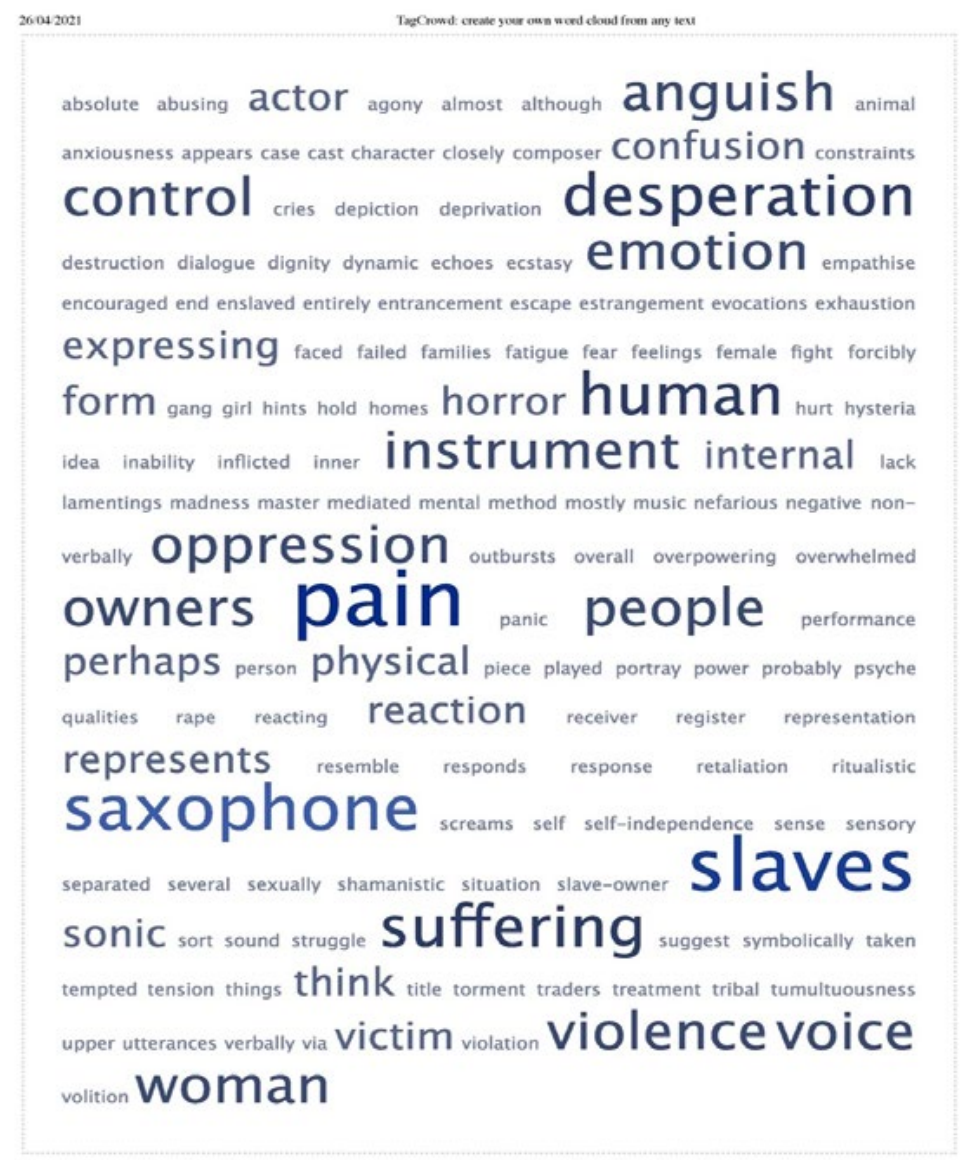

Figure 2: Word Cloud demonstrating the most used words describing what the participants felt about excerpt of SWEET TOOTH (2018).

Participants were then asked about their perception of the relationship between the instrument and the performer. The majority (81.25\%) of participants described a reaction between the instrumentalist and performer and how the saxophone appeared to be controlling the performer. Others cited that they felt there was some kind of physical pain (whether empathetic pain or otherwise would require further investigation) and that there was some form of opposition between instrumentalist and performer. The word cloud below shows the most used words in response to the question 'in your opinion, what is the relationship between the instrument and the performer in this excerpt?' (Figure 3).

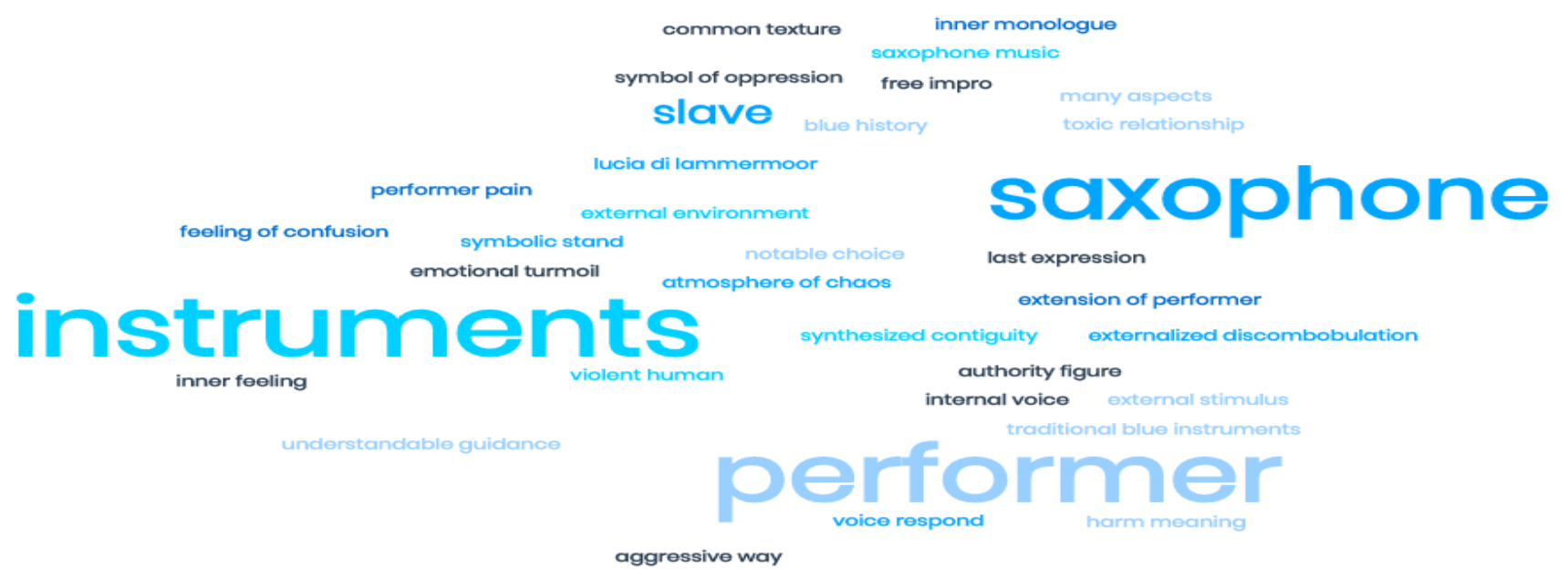

Figure 3: Word Cloud demonstrating the participant's thoughts on the relationship between instrumentalist and performer 
Participants were then asked how effective (this was not defined further), they felt the orchestrations were in this excerpt. A large majority (92.5\%) described the orchestration as effective and agreed that it helped to paint a picture. One participant argued that it was not effective and was un-emotive; one participant noted that they were unsure. Following this there was space for those who wished to additional thoughts. Here, one participant commented that watching the excerpt made them feel uncomfortable and they wished they could cut it short, noting that the slaves could not (cut it short) and were trapped in 'it'. Another participant commented that the piece was 'brilliantly done' and that it was 'unsettling and unexpected'. Most participants answered that the saxophone and voice could be heard in this extract. They also collectively agreed that the timbre created was harsh, piercing, shrill and strong. A follow-up question asked for further comments. Some elaborated further on their emotions noting that the music was 'maybe not accessible for all', and that 'the music is difficult to listen to ... which conveys the painful experience of slavery'.

To understand how participants understood aesthetics they were asked whether instruments added to the overall aesthetic of the piece (again, not defined further). In response, $23.8 \%$ argued that the instruments created a sense of tension and $18 \%$ of the participants felt that they created a sense of danger. As a follow up, participants were asked to describe their feelings about the piece (from what they had seen). The most frequent answers were anxiety, horror, interest, and epithetic pain. It is also interesting to note that option 'aesthetic appreciation' (although not defined) was chosen by $42.5 \%$ of the respondents. One participant cited that they felt 'concern' but did not elaborate further.

\section{Case Study Two: BRETHREN (2016)}

This set of questions concerned the second case study, BRETHREN (2016). BRETHREN was composed by James Whittle as a response to the 2015 Mediterranean refugee crisis and explores how a community caught in conflict, upheaval and isolation can rebuild and move forward together (Call for Performers, n.d.).

Participants were again asked to watch and listen to a short video clip which showed violinists moving around the stage making wild gestures with their arms and occasionally playing a note. Participants were first asked how the instrumentation helped the composer to demonstrate the concept of family or 'collecting' (bringing together/gathering), which was purposely left open to interpretation. Four participants felt that the material did not demonstrate family at all, however the overall consensus was that a sense of family was identifiable even if at times it felt there was 'dysfunction' in the music. When asked 'how do you think the instruments are being used as characters?' there was a split in responses. Many participants (29.16\%) cited a sense of 'speaking' or 'chitter-chatter' as if debating or part of a crowd.
Most participants (93.75\%) did not make a link between movement and family, stating that they 'did not think it worked very well to portray characters' or that 'it looked odd'. These answers anticipated the following question: 'Would you agree that there is a sense of family created by the instruments?' to which just under half (37.5\%) of the participants responded that there was a 'distinct sense of family', while the same amount noted that they were not sure. Sixteen (33\%) participants left additional comments with one commenting that they felt the music theatre initially showed family in relation to the refugee crisis but noted that as they saw the second clip, they considered the 'instrumental families' such as strings or percussion. The next question asked 'how would you describe how the instruments sound (the timbre) in this passage? There were no notable findings here, but it is interesting that most participants sprung towards 'harsh' as a main descriptor. This question was extremely difficult to answer due to the many possible answers and the fast-changing music, which one participant goes on to mention in the next 'additional comments' box. Notably, one participant stated that they couldn't connect emotionally to this material in the same way they did with the SWEET TOOTH material, commenting that: 'this didn't connect with me emotionally at all. Unlike the sweet tooth extracts - I've never seen either in full'.

The next question asked how the instruments added to the overall aesthetic of the piece (not defined). There were also no notable findings here - most participants answered that there was a sense of tension (27\%) and danger (17.2\%), although they felt ambivalent about what was happening. The responses to this piece demonstrate that it failed to capture the audience's imagination as much as SWEET TOOTH did. This may also be because the second piece came at the end of a long survey.

The next question asked the about the perceived atmosphere. Most (20.9\%) participants described the atmosphere as frightening. While the staging did not imply danger per se, the experimental nature of the music and sense of urgency obviously stirred these feelings within the participants which would be interesting to explore further.

Finally, participants were asked how the combination of music and staging made the audience feel. The overwhelming response by over half (58.3\%) of the participants was that they were left confused, with one person even stating that they felt disgust. Only one participant left an additional comment, saying that they expected some kind of climax which was not included in the video excerpts. 
These findings summarise data collected from an online questionnaire which opened in February and closed in July 2021. The aim of the research was to discover whether orchestration was an aesthetic of music theatre which audiences find alienating or difficult to comprehend. Results show that audiences are able to connect with some staged material more easily than others. One major conclusion that can be drawn is that participants felt more emotionally connected to SWEET TOOTH than BRETHREN. The subject material and presentation of SWEET TOOTH is more explicit, and it is very easy for audiences to grasp what is happening both in the music and on stage. BRETHREN is less explicit and more abstract in its nature. There are arguments as to the best methods of theatrical presentation, but this research has shown that audiences respond more enthusiastically to work which they do not have to fight to understand. There is evidence that there is a relationship between emotional language and maturity and aesthetic understanding which could be explored further.

It can be argued that audiences are aware of the effect instrumentation and orchestration has on a performance, but only when explicitly questioned on the topic. This hypothesis would benefit from further testing with a specific and detailed survey of audience responses to the use of extended technique in musico-theatrical practices. It is, however, encouraging to see that a majority of participants stated that they had previously attended a music theatre performance (although this was not clearly defined) and most participants (87.5\%) stated that they would be likely to see a music theatre performance. This implies that there is general interest in the art form. It can also be argued that this was an effective form of data collection which, with some fine tuning, could be employed for further research.
Each music theatre piece provided illuminating responses, and it was interesting that these artworks could elicit many negative comments. This provides evidence that there is a possible link between lack of aesthetic appreciation (the admiration of beaty in art) and negative emotional response.

Further research in the form of one-to-one workshops will be the next step in data collection. Collecting data in-person will enable researchers to fill in the gaps in observed data, such as body language, eye contact and general attitudes towards the subject material. Specifically, this will help to determine variables such as the duration of participants' engagement/ concentration and what interests them the most by observing the body language demonstrated whilst watching the material. Other areas of investigation could include how to identify and articulate complex emotion through text, as language can be limiting if participants do not hold the appropriate lexicon to describe these complex emotions. The workshops could also allow for discussion between researcher and participant, thereby allowing follow-up questions which were not possible with the online survey. Further data collection will make it easier to draw conclusions as to the state of the art form and offer some predictions for its future development. This study acknowledges the need for further research on the elucidation of orchestration and instrumental aesthetics in the music theatre art form and aims to foster and champion the development of music theatre for the future.

\section{REFERENCES}

Adlington, R. (ed.), 2020. New Music Theatre in Europe: Transformations between 1955-1975. 1st edition. Routledge.

Boerner, S. \& Jobst, J., 2013. "Enjoying theater: The role of visitor's response to the performance." Psychology of Aesthetics, Creativity, and the Arts 7, 391-408. https://doi.org/10.1037/a0034570

Boerner, S. \& Jobst, J., 2008. "The Perception of Artistic Quality in Opera - Results from a Field Study." Journal of New Music Research, (37): 233-245. https:// doi.org/10.1080/09298210802542008
Chan, M., Tung, W. \& Hoyan, C., 2019. "Exploring Theatre Experiences among Hong Kong Audiences." Cogent Arts \& Humanities, 6(1). DOI: https://doi.org/10. 1080/23311983.2019.1588689.

Coker, T., 2006. Dramma Per Musica - Towards a New Music Theatre. PhD Thesis. Reading: University of Reading.

Devlin, G., 1992. Begger's Opera: A discussion document on small-scale touring opera and musictheatre in the U.K. Calouste Gulbenkain Foundation, London. 
Hall, M., 2015. Music Theatre in Britain, 1960-1975.

Illustrated edition. ed. Woodbridge, Suffolk, UK: Boydell Press.

Jobst, J. \& Boerner, S., 2011. "Understanding customer satisfaction in opera: first steps toward a model:

Understanding customer satisfaction in opera." Int. J. Nonprofit Volunt. Sect. Mark. (16): 50-69. https://doi. org/10.1002/nvsm.394.

Rebstock, M. \& ITI Germany (ed.), 2020. Freies Musiktheater in Europa / Independent Music Theatre in Europe: Vier Fallstudien / Four Case Studies. Transcript Verlag.
Salzman, E., 2002. "From Stage to Page: MusicTheater in Print." Theater, 32(1): 63-71. DOI: 10.1215/01610775-32-1-63.

Verstraete, P., 2009. The Frequency of Imagination: Auditory Distress and Aurality in Contemporary Music Theatre. PhD Thesis. Amsterdam: University of Amsterdam.

Whittle, J., no date. CALL FOR PERFORMERS: BRETHREN for roaming orchestra - James Whittle. Available at: https://james-whittle.co.uk/composition/ call-for-performers-brethren-for-roaming-orchestra/ [Accessed 9 December 2021].

-., no date. Theatres Act 1968. Statute Law Database. Available from: https://www.legislation.gov.uk/ ukpga/1968/54 [Accessed 9 January 2022].

\section{B I O G R A P H Y}

Ryan Thomas Green is a second year PhD candidate in Music at the Interdisciplinary Centre for Computer Music Research, School of Society and Culture, University of Plymouth. He is interested in fostering new forms of musico-theatrical performance. 